\title{
Delay in gallbladder emptying during the perimenopausal period
}

A. Petroianu ${ }^{1}$,

L.C. O liveira ${ }^{2}$ and

M.I. Vieira ${ }^{2}$

\author{
Departamentos de ${ }^{1}$ Cirurgia and ${ }^{2}$ Ginecologia e O bstetrícia, \\ Faculdade de Medicina, Universidade Federal de M inas Gerais, \\ Belo Horizonte, MG, Brasil
}

\author{
Correspondence \\ A. Petroianu \\ Av. Afonso Pena, 1626, apto. 1901 \\ 30130-005 Belo Horizonte, MG \\ Brasil \\ Fax: +55-31-274-7744 \\ Research supported by $\mathrm{CNPq}$ \\ and FAPEMIG.
}

......................

Received June 18, 1999

Accepted June 30, 2000

\section{Abstract}

A pilot study has ascribed an important role in gallbladder motility and emptying to the perimenopausal period. To assess the effect of this period on gallbladder emptying and cholelithogenesis, 25 women in the perimenopausal period without gallbladder disease were submitted to cholangiography and two ultrasound exams. The time for gallbladder emptying and the presence of cholelithiasis were assessed. All patients presented a delay in gallbladder emptying with no relationship to the pre- or postmenopausal period. This finding was not related to lithogenesis. Gallbladder emptying time is longer during the perimenopausal period.

Age and gender are thought to influence the pathogenesis of gallstones. The classical characterization of the patient with cholelithiasis is a fat woman in her forties. However, the relation between these parameters and gallstones has not been well established.

Previous studies described the influence of sex hormones on gallbladder emptying. A significant delay in gallbladder emptying during the luteal phase of the menstrual cycle and an increased incidence of cholelithiasis in women using sex hormones have been reported (1-5). Experimental investigations have shown the sensitivity of the gallbladder to neurohormonal stimulation and the inhibitory effect of sex hormones, mainly progesterone, on gallbladder contractility $(3,6)$.

Menopause is defined as cessation of menstruation, ending the fertile part of life. A delay in gastric and enteric transit has been established during the perimenopausal period (6-10). Hormone replacement therapy for postmenopausal women has the advan-

\section{Key words}

- Gallbladder emptying

- Menopause

- Cholelithiasis

- Ultrasound

- Cholangiography tages of relieving symptoms, such as hot flushes, and preventing the risk of osteoporosis, but increases the incidence of gallstones $(7,10,11)$.

Impairment of gallbladder emptying is increasingly suspected to be a potential pathophysiological factor in the development of gallstones $(5,9,12)$. The longer gallbladder emptying delay in women compared to men and the coincidence of elements related to decreased gallbladder emptying and the pathogenesis of gallstones support this hypothesis.

A pilot report ascribed an important role related to gallbladder motility and emptying to the perimenopausal period (13). The main purpose of the present study was to investigate the time of gallbladder emptying during the perimenopausal period, and to determine whether a possible delay in gallbladder emptying is related to a higher incidence of cholelithiasis.

A prospective and randomized study was 
carried out on 25 women ranging in age from 39 to 65 years $($ mean $=52.3 \pm 4.2$ years $)$ (Table 1). All women were patients of the gynecologic ambulatory of our hospital and were considered to be in the perimenopausal period, based on irregular menstruation or its cessation, vasomotor symptoms and decreasing estrogen levels. The subjects were not taking any medication, including hormone replacement therapy.

These patients were submitted to an interview and physical examination. Informed consent was obtained from all women participating in the present investigation, in accordance with the Ethics Committee of our hospital and following the principles of the Helsinki Declaration. The protocol of the present study was approved by the Ethics Committee of the University Hospital of the

Table 1 - Gallbladder emptying time in 25 women in the perimenopausal period, and presence of gallstones at ultrasound during follow-up.

*Patient age was that at the time of the first exam.

\begin{tabular}{|c|c|c|c|c|}
\hline $\begin{array}{l}\text { Hospital } \\
\text { registration } \\
\text { No. }\end{array}$ & $\begin{array}{c}\text { Age } \\
\text { (years)* }\end{array}$ & $\begin{array}{l}\text { Gallbladder } \\
\text { emptying } \\
\text { time (h) }\end{array}$ & $\begin{array}{l}\text { Time of the } \\
\text { subsequent } \\
\text { ultrasound (years) }\end{array}$ & $\begin{array}{l}\text { Presence of } \\
\text { gallstones }\end{array}$ \\
\hline 274154 & 51 & 24 & 6 & No \\
\hline 206554 & 43 & 72 & 7 & No \\
\hline 377980 & 47 & 12 & 2 & No \\
\hline 320121 & 47 & 48 & 2 & No \\
\hline 157691 & 45 & 72 & 7 & No \\
\hline 116301 & 57 & 24 & 3 & No \\
\hline 229048 & 52 & 8 & 5 & No \\
\hline 367548 & 58 & 12 & 2 & No \\
\hline 375948 & 54 & 24 & 3 & No \\
\hline 169842 & 59 & 48 & 2 & No \\
\hline 176951 & 54 & 48 & 2 & No \\
\hline 225950 & 52 & 48 & 3 & No \\
\hline 197493 & 58 & 48 & 4 & No \\
\hline 355693 & 50 & 36 & 3 & No \\
\hline 160198 & 39 & 24 & 3 & No \\
\hline 374139 & 58 & 48 & 3 & No \\
\hline 354288 & 46 & 36 & 4 & No \\
\hline 127328 & 55 & 24 & 6 & No \\
\hline 188223 & 44 & 72 & 3 & No \\
\hline 226763 & 58 & 48 & 3 & No \\
\hline 210133 & 53 & 24 & 7 & No \\
\hline 280266 & 65 & 24 & 3 & No \\
\hline 407504 & 53 & 12 & 2 & No \\
\hline 312682 & 60 & 24 & 5 & Yes \\
\hline 194662 & 50 & 72 & 5 & Yes \\
\hline
\end{tabular}

Federal University of Minas Gerais.

An upper abdominal ultrasonography was performed for gallstone diagnosis. The presence of cholelithiasis was a criterion of exclusion from this investigation. An oral cholecystogram was performed with radiographs during the first $8 \mathrm{~h}$, and then every $24 \mathrm{~h}$ until the gallbladder was completely empty. During this time, the patients were instructed not to change their activities or eating schedule and no food recommendation was made.

A second ultrasound exam was scheduled for at least two years after the first exam. Thus it was performed over a period of 2 to $7(3.8 \pm 2.1)$ years to determine the occurrence of cholelithiasis after the first study (Table 1).

All patients presented an important delay in gallbladder emptying ranging from 8 to 72 $\mathrm{h}($ mean $=37.3 \pm 16.8)($ Table 1$)$. There were no significant differences in age or being in the pre- or postmenopausal period among subjects.

Echographic images of gallstones were recorded in two patients five years after the first study (Table 1). One of these patients was a 65-year-old woman who had been taking oral hormonal replacement for the last three years. The second patient was a severely obese 55-year-old woman who took no medication.

We did not perform any statistical tests because we did not have a group for comparison. We only verified a significant delay in gallbladder emptying by comparing the exams with normal exams previously performed by the same service in young and healthy women (14).

Gallbladder emptying is controlled by a complex interaction between intestinal and extraintestinal neurohormonal factors. Motility disorders of the gallbladder are considered to be increasingly a potential pathophysiological factor for the development of gallstones.

The present investigation was performed by oral cholecystography in order to assess 
the emptying of orally administered iodine contrast from the gallbladder. Other imaging exams may fail to show this function during a longer period such as more than $90 \mathrm{~h}$. Cholecystography clearly showed that the contrast did not completely exit the gallbladder within less than $24 \mathrm{~h}$ as it is expected since the gallbladder fills and empties several times per day. We did not use any special stimulus for gallbladder emptying because we wanted to investigate the function of this organ under normal conditions.

The present radiological study demonstrated an important delay in gallbladder emptying during the perimenopausal period in all patients. We did not test the age effect, but only the presence of hormonal disturbances due to the perimenopausal period. Previous studies with the same method showed that complete emptying of a normal gallbladder requires about $4 \mathrm{~h}$ (14). In this investigation, only 4 of the 25 women studied showed gallbladder emptying during less than $24 \mathrm{~h}$, but even these patients presented a longer than normal emptying time.

Patients with cholecystitis may have a longer gallbladder emptying time (15-18). The pathogenesis of this finding is not well understood $(16,18,19)$. However, none of our patients presented cholecystitis at the time of the first examination or during the follow-up period. The two patients with cholelithiasis did not show any sign or symptom related to inflammatory gallbladder disease. The small number of patients who developed gallstones cannot be explained.

In this investigation, we did not use any control group because we had the data of normal gallbladder emptying from a previous study conducted in the same Radiological Unit and using the same method, but on a different group of subjects (19). Thus, we considered unnecessary to submit young normal women or men without any complaint to radiological studies.

In conclusion, the present study confirmed that gallbladder emptying time is longer during the perimenopausal period. However, this impairment of gallbladder emptying does not seem to be an early risk factor in the pathogenesis of gallstones. Further studies and a longer follow-up period are necessary to verify the late consequence of these findings.

\section{Acknowledgments}

The authors gratefully thank the Radiological Unit, Hospital das Clínicas, Universidade Federal de Minas Gerais, for the gallbladder examinations.

\section{References}

1. Nilsson S \& Stattin S (1967). Gallbladder emptying during the normal menstrual cycle. Acta Chirurgica Scandinavica, 133: 648-652.

2. Braun B \& Dormeyer HH (1982). Changes in gallbladder motor function during the female cycle. Klinische Wochenschrift, 60: 1357-1362.

3. Fried GM, Ogden WD, Fagan CJ , Wiener I, Inoue K, Greeley J r GM \& Thompson J C (1984). Comparison of cholecystokinin release and gallbladder emptying in men and in women at estrogen and progesterone phase of the menstrual cycle. Surgery, 95: 284-289.

4. Kakar F, Weiss NS \& Strite AS (1988). Non-contraceptive estrogen use and the risk of gallstone disease in women. American J ournal of Public Health, 78: 564566.

5. Grodstein F, Colditz GA, Hunter DJ , Manson J E, Willett WC \& Stampfer MJ (1994). A prospective study of symptomatic gallstones in women. Obstetrics and Gynecology, 84: 207-214.

6. Keane P, Colwell D, Baer HP, Clanachan AS \& Scott GW (1986). Effects of age, gender and female sex hormones upon contractility of the human gallbladder in vitro. Surgery, Gynecology and Obstetrics, 163: 555-560.

7. Honoré LH (1980). Increased incidence of symptomatic cholesterol cholelithiasis in perimenopausal women receiving estro- gen replacement therapy. J ournal of Reproductive Medicine, 25: 187-190.

8. Wedmann B, Schmidt G, Wegener M, Coenen C, Ricken D \& Altoff J (1991). Effects of age and gender on fat-induced gallbladder contraction and gastric emptying of a caloric liquid meal. American J ournal of Gastroenterology, 86: 1765-1770.

9. Russo F, Cavallini A \& Messa C (1993). Endogenous sex hormones and cholesterol gallstones. American J ournal of Gastroenterology, 88: 712-717.

10. Grodstein F, Colditz GA \& Stampfer MJ (1994). Postmenopausal hormone use and cholecystectomy in a large prospective study. Obstetrics and Gynecology, 83: 5-11. 
11. Ravn SH, Rosenberg J \& Bostofte E (1994). Postmenopausal hormone replacement therapy. European J ournal of Obstetrics, Gynecology, and Reproductive Biology, 53: 81-93.

12. La Morte W, Schoetz J r DJ \& Brikett DH (1979). The role of the gallbladder in the pathogenesis of cholesterol gallstones. Gastroenterology, 77: 580-592.

13. Petroianu A (1989). Gallbladder emptying in perimenopausal women. Medical Hypotheses, 30: 129-130.

14. Lázaro da Silva A \& Silva RG (1994).
Colecistografia oral retardada no estudo da discinesia biliar. Arquivos de Gastroenterologia, 31: 87-91.

15. Sacchetti G, Mandelli $V$ \& Roncoroni L (1973). Influence of age and sex on gallbladder emptying induced by a fatty meal in normal subjects. American J ournal of Roentgenology, 119: 40-45.

16. Koehler RE, Stanley RJ \& DiCroce J (1978). Prolonged gallbladder opacification after oral cholecystography. Radiology, 128: 601-603.

17. Nora PF, McCarthy W \& Sanez N (1974).
Cholecystokinin cholecystography in acalculous gallbladder disease. Archives of Surgery, 108: 507-511.

18. Adams TW \& Foxley EG (1976). A diagnostic technique for acalculous cholecystitis. Surgery, Gynecology and Obstetrics, 142: 168-170.

19. Banner MP, Bleshman MH \& Speckman J M (1979). Persistent gallbladder opacification after iopanoic acid cholecystography. American J ournal of Roentgenology, 132: 51-54. 